\title{
Spasm and flexion-relaxation phenomenon response to large lifting load during the performance of a trunk flexion-extension exercise
}

\author{
Yanjun Ma and Xinhai Shan
}

\begin{abstract}
Background: The flexion relaxation phenomenon (FRP) has been widely investigated. Nevertheless, no study has been reported on the FRP as well as spasm response to large lifting load. The aim of this study was to evaluate the effect of large lifting load on the FRP response and spasm during execution of a flexion-extension exercise.

Methods: Twenty-two healthy male university students without low back pain history participated this study. Subjects randomly performed three trials of trunk flexion-extension cycles of $5 \mathrm{~s}$ flexion and $5 \mathrm{~s}$ extension in each of 4 conditions (three large lifting loads of 15,20 and $25 \mathrm{~kg}$ and one lifting load of $0 \mathrm{~kg}$ for comparison). Surface EMG from bilateral erector spinae was recorded during the performance of a trunk anterior flexion-extension exercise. The relaxation phase was determined through the onset of electromyography (EMG) signals. Spasm was evaluated in the relaxation period. The mean normalized electromyography (NEMG) was derived from the raw EMG.

Results: Spasm was observed in more than $45 \%$ of the individuals and the intensity of muscle activation was increased by more than $78 \%$ in the relaxation phase.

Conclusions: A large lifting load could lead to a high prevalence of spasms as well as a high intensity of muscle activations on erector spinae muscle in the relaxation period, which may be associated with the development of low back disorder during the performance of a flexion-extension exercise.
\end{abstract}

Keywords: Low back pain, Lifting load, Trunk flexion-extension, Erector spinae, Muscular intensity

\section{Background}

Low back pain (LBP) is a serious public health problem in many developed countries [21]. In the United States, for instance, according to a recent report from the Center for Disease Control and Prevention (CDC), back injury in adults is ranked second among the most common reasons that lead to disability [5]. LBP is reported to be responsible for $13 \%$ of sick days of all the working population [2], as well as the over 90 billion dollars in annual medical expenses [14, 18]. Despite this, the exact etiology of LBP is still poorly understood [3].

\footnotetext{
* Correspondence: xhshan@sdnu.edu.cn

Biomechanics Laboratory, College of Physical Education, Shandong Normal University, 88 Wenhua East Road, Jinan, Shandong 250014, People's Republic of China
}

Epidemiologically, trunk bending as well as lifting activities is thought to be a risk factor for the development of LBP [19, 35]. In a previous experimental investigation, Solomonow et al. [31] found that during sustained static lumbar flexion, bilateral spasms were occasionally observed on the erector spinae (ES). In addition, after sustained static lumbar flexion, the relaxation period (from the time of the EMG-off in the flexion phase to the time of the EMG-on in the extension phase) in the FRP on the ES was found to be shorter during the execution of a trunk anterior flexion-extension. Based on the mechanism of a synergistic load sharing between passive tissues and active muscles (e.g., ES) in the FRP [8-10], Solomonow et al. [31] pointed out that the increase of ES muscle activation would indicate the compensation for the decreased ability to resist the tension of stretching 
passive tissues, which might be closely related to LBD. Recently, an increase of muscle activation in the FRP has also been found after prolonged static compression [28]. The increase of the muscle activation is postulated to be associated with the relative lengthening of ligaments due to the shrinkage of intervertebral discs in parallel with the neural adaptation (synergy or inhabitation) in response to changes in the mechanical properties of the passive tissues, which may be damaged to some degree after prolonged compressive loading [28]. Accordingly, the load on the spine may be a contributory factor to the development of $\operatorname{LBD}[4,13,16,24]$.

As a common activity in daily life and sports practice, load lifting increases the external moment in the lumbosacral joint [32] as well as the load on passive tissues [7, 12]. However, as it is widely known, no spasm on ES muscle has been reported to occur during the execution of trunk flexion-extension exercises with load lifting. Spasms are random and unpredictable EMG discharge signals in intensity and/or duration time. They might be a strong LBD indicator, representing some type of micro-damage in passive tissues (dorso-lumbar fascia and posterior ligaments) [31, 33].

Previous investigations on loaded trunk flexionextension exercises have used less than $10 \mathrm{~kg}$ of lifting load. However, it was found that the load seemed to have no effect on the FRP [25]. Actually, the authors speculated that the results about the FRP response might be different when the lifting load was larger $(>10 \mathrm{~kg})$.

Accordingly, the purpose of the present study was to evaluate the occurrence of spasms and the effect of large lifting load on the FRP response. It was hypothesized that, with a large lifting load, spasms may be observed on bilateral ES muscles during the relaxation phase in the FRP. It was also anticipated that, in the relaxation period, muscle activation intensity would significantly increase in order to compensate for the load increase in passive tissues.

\section{Methods}

\section{Participant descriptions}

Twenty-two male subjects were recruited from the University's student population to participate in the study after approval by the local ethics committee. Participants read and signed a consent form before participating in the study. Demographic information was collected using a questionnaire to assess prospective participants for eligibility according to the inclusion and exclusion criteria. Their age, weight and height (mean (SD)) were 24(1) years, 71(6.5) kg, 177(5) cm, respectively.

Participants without current complaints of back pain were included in the study. Exclusion criteria included any uncorrectable spine pathology, history of spine surgery, hip conditions that would not allow participants to fully flex and extend their hips comfortably, current back pain, consultation of a physician for back pain in the last year.

\section{Flexion relaxation measurements}

The pre-gelled (Ag-AgCl) disposable surface EMG electrodes were applied at the L3-L4 level over the bilateral ES muscles (about 4-6 cm lateral from the midline). Inter-electrode distance was $2.5 \mathrm{~cm}$, and the electrodes were oriented longitudinally along the muscle. A reference electrode was placed on the left anterior superior iliac crest. The EMG signals were amplified (Biovision, Wehrheim, Germany) $\times 1000$ at a frequency band-pass of $10-500 \mathrm{~Hz}, 1 \mu \mathrm{V}$ noise referred-to-input, and CMRR of $120 \mathrm{~dB}$. The Input impedance was $10^{9} \mathrm{k} \Omega$. The resulting signal was sampled at $1000 \mathrm{~Hz}$ via a 14-bit data acquisition system and stored for later processing.

\section{Experimental protocol}

The skin was cleansed and gently abraded with alcohol prep pads before attachment of the EMG electrode. The electrodes were placed as described above, and a signal check was conducted to ensure the quality of the EMG signals.

Before trunk flexion-extension, maximum voluntary contraction (MVC) was obtained for the left and right ES muscles for $5 \mathrm{~s}$ in one repetition by applying resistance in the Beiring-Sorensen position [6, 20].

The subject was then required to stand on a wood frame with the same height as the customized wooden box, and to perform a trunk flexion-extension while standing, randomly in each of 4 conditions (three large lifting 15, 20 and $25 \mathrm{~kg}$ and one lifting load of $0 \mathrm{~kg}$ ). The box was designed by adjusting the amount of weight to be about $5 \mathrm{~kg}$ with dumbbells, which were set through a wooden rod that was fixed inside the box (Fig. 1a). The total amount of lifting load was reached by putting a barbell above the box. For the safety reasons, the barbell was also set through the rod. During the performance of the exercises, all participants were required to put their feet shoulder width apart, keep their knees straight during the test, and contact the toes of feet with their finger nails (in $0 \mathrm{~kg}$ ) or with the box contacting the floor lightly in full flexion.

Each trial consisted of $10 \mathrm{~s}$ total time: $5 \mathrm{~s}$ from upright posture to full anterior flexion, and $5 \mathrm{~s}$ from full flexion back to upright posture [28].

The timing for each trial was set by a metronome with one beat per second. Each participant performed a full flexion trial, with 2 min rest between each load condition.

\section{Data analysis}

EMG signals were full-wave rectified, then dual-pass filtered through a fourth order Butterworth filter with an effective cutoff frequency of $6 \mathrm{~Hz}$ [34] to obtain the 

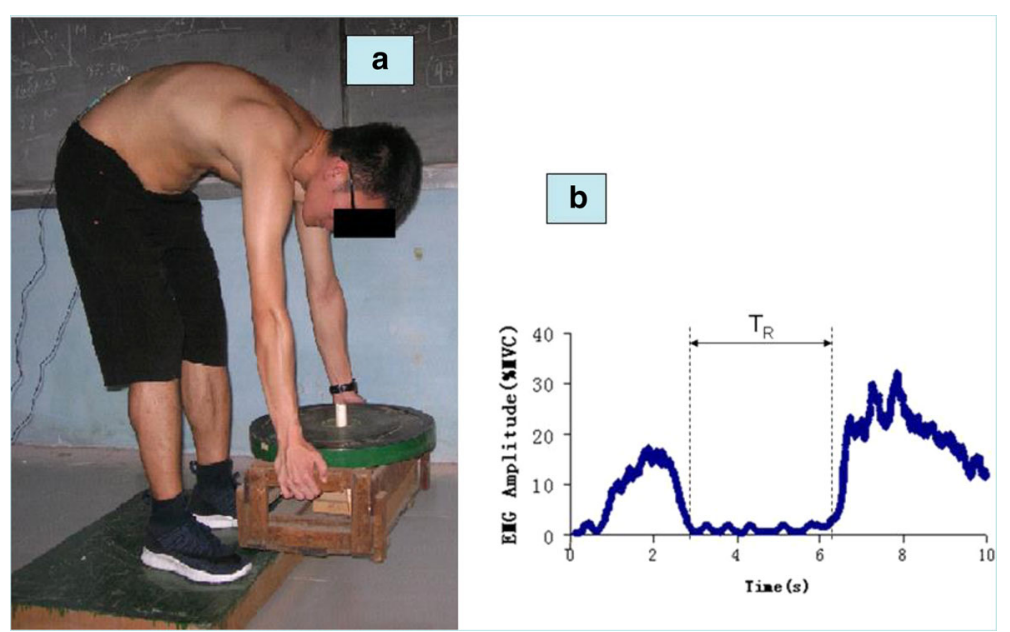

Fig. 1 a. A subject during flexion phase of a flexion-extension test in $15 \mathrm{~kg}$ lifting condition. $\mathbf{b}$. The exemplar averaged bilateral EMG amplitude (MVC\%) of a participant during flexion-extension performance with $0 \mathrm{~kg}$ hand load condition. The parallel vertical dotted lines represent EMG-off (left) and EMG-on (right) timing. $T_{R}=$ the time of relaxation period from EMG-off to EMG-on

mean absolute value (MAV). For MVC, the value was achieved by averaging the MAV in the middle $3 \mathrm{~s}$ (eliminating $1 \mathrm{~s}$ at the beginning, and $1 \mathrm{~s}$ at the end of the total $5 \mathrm{~s}$ ). For each trial, the MAV was normalized to the MVC value to get EMG amplitude (\% MVC) bilaterally. Then, EMG amplitudes from bilateral ES muscles were averaged to represent the bilateral ES muscle activations $[17,27]$. A threshold level of $3 \%$ of the MVC was used to determine the relaxation period (the beginning and the end of the myoelectric activity) (Fig. 1b) [29].

The NEMG [29] was utilized to represent the intensity of the muscle activation, which was calculated as an averaged EMG (MVC\%) in the relaxation phase using the following Equation (Eq.):

$$
\mathrm{NEMG}=\frac{1}{N} \sum_{i=1}^{N} E M G_{i}
$$

Where, $\mathrm{N}$ denotes the length of the relaxation phase $\left(T_{R}\right.$ in Fig. 1b). NEMG values were normalized by the $0 \mathrm{~kg}$ load condition (Table 1).

Table 1 Statistical results of Spasms and NEMG in relaxation period

\begin{tabular}{|c|c|c|c|c|}
\hline \multirow{2}{*}{$\begin{array}{l}\text { Lifting Load } \\
(\mathrm{kg})\end{array}$} & \multicolumn{2}{|l|}{ Spasms } & \multicolumn{2}{|c|}{ NEMG(\%MVC) (Mean(SD)) } \\
\hline & Case & prevalence & Absolute (\%MVC) & Normalized \\
\hline 0 & 0 & 0 & $1.05(0.21)$ & $1.00(0.00)$ \\
\hline 15 & $10^{\mathrm{a}^{* *}}$ & $45 \%^{a^{* *}}$ & $1.87(0.33)^{\mathrm{a}^{* *}}$ & $1.78(0.09)^{a^{* *}}$ \\
\hline 20 & $15^{a^{* *} b^{*}}$ & $68 \% \%^{\mathrm{a}^{* *} \mathrm{~b}^{*}}$ & $2.13(0.32)^{a^{* *}}$ & $2.03(0.10)^{a^{* *} b^{*}}$ \\
\hline 25 & $18^{\mathrm{a}^{* *} \mathrm{~b}^{* *} c^{*}}$ & $82 \%{ }^{a^{* *} b^{* *} c^{*}}$ & $2.37(0.40)^{a^{* *} b^{* *}}$ & $2.26(0.12)^{a^{* *} b^{* *} c^{*}}$ \\
\hline
\end{tabular}

${ }^{* *} P<0.01 ; * P<0.05$ ( $a=v s .0$ kg; $b=v s .15$ kg; $c=$ vs. 20 kg). (NEMG = mean normalized EMG)
The evaluation of spasms during the relaxation period is performed in two steps. The first step was a qualitative analysis. Spasm-like signals were preliminarily separated from the raw signals of all trials if there were random and unpredictable EMG signals in intensity and/or duration time (Fig. 2). The second step was a quantitative analysis. A threshold, twice the NEMG signal with the $0 \mathrm{~kg}$ load condition during the relaxation period was utilized to ultimately evaluate the spasms.

The SPSS software version 15.0 (SPSS, Inc., Chicago,IL, USA) was used for all statistical analysis. To test the effect of a large load, a Chi-Square test was performed on both the case and prevalence of spasms between groups. Additionally, repeated measures analysis of variance (ANOVA) test was used on both the absolute and normalized NEMG. A post-hoc test with a Bonferroni adjustment was also used to compare differences in the NEMG between groups. Significance was set at $p \leq 0.05$ for all measurements.

\section{Results}

A significant effect of large load lifting $(p<0.05)$ was found both on the case and the prevalence of spasms. Among the total 22 participants, there were 10, 15 and 18 spasm cases in the load conditions of 15,20 and $25 \mathrm{~kg}$ with a prevalence of $45 \%, 68 \%$ and $82 \%$, respectively (Table 1).

In the relaxation period, significant effect of large load lifting $(p<0.05)$ was also found both on the absolute and normalized NEMG. With the increase of the lifting load, the normalized NEMG exhibited a significant increase $(p<0.05)$. The normalized NEMG in large lifting experienced an increase of $78 \%-126 \%$ compared with that in $0 \mathrm{~kg}$ load lifting. 

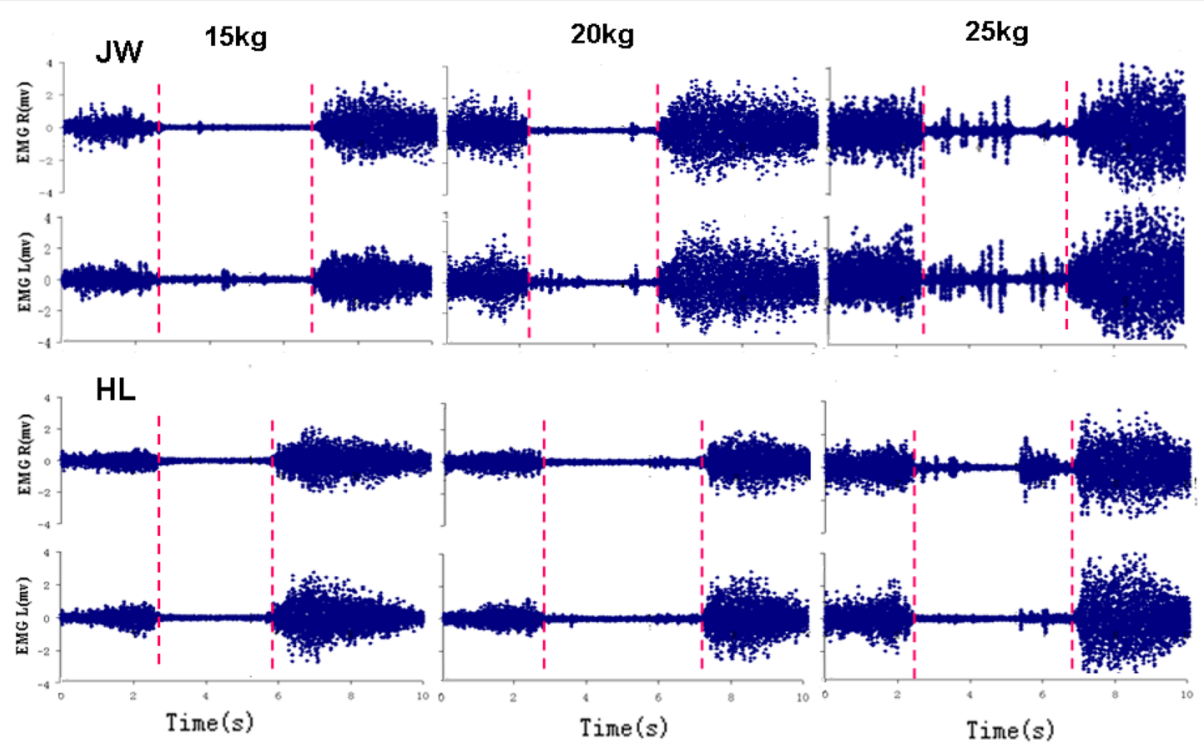

Fig. 2 Two samples (JW and HL) of bilateral EMG recordings from ES during flexion-extension performance with large lifting load condition, respectively. During relaxation period in $15 \mathrm{~kg}$ condition, subject JW shows some spasms in a form of low amplitude with sustained discharge mainly on left ES while HL having no spasms. In $20 \mathrm{~kg}$ condition, JW shows some spasms in form of sporadic potential discharge mainly on left ES while HL having a little spasm. In $25 \mathrm{~kg}$, both JW and HL shows the spasms obviously triggered with sporadic large amplitude action potential discharge bilaterally. The vertical parallel dotted lines represent EMG-off (left red) and EMG-on (right red) timing

\section{Discussion}

The main results of this study showed that, during anterior trunk flexion-extension with a large lifting load, spasms occurred with a high prevalence, and the normalized NEMG showed a significant increase in the relaxation period.

Unlike the finding by Sarti et al.[25], which indicated that a light load $(<10 \mathrm{~kg})$ has no effect on FRP, a significant effect of a large load on the normalized NEMG signal was detected in the relaxation period. Compared with the $0 \mathrm{~kg}$ load, the NEMG signal increased $78 \%$ with the $15 \mathrm{~kg}$ whereas the increased signal intensity reached $126 \%$ with the $25 \mathrm{~kg}$. It was suggested that the NEMG signal could represent the intensity of the muscle activation during the relaxation phase [29]. They suggested that the higher NEMG in the ES muscle during the relaxation phase might be linked to fatigue during sustained trunk flexion. However, it is obvious that fatigue was not the case in the study since the participant had enough rest time between trials and the performance of the exercise in one trial lasted only $10 \mathrm{~s}$. Thus, it was more likely to be a sustained muscle activity, which was commonly detected in back pain patients with ES muscle activity ([10]; Floyd and Silver, 1955). Therefore, muscle activation related to the large load lifting during the relaxation period may indicate a compensation for passive tissues $[15,26]$, which is closely related to LBD $[4,13,31]$.

When lifting a large load, spasms were observed in more than $45 \%$ of participants with the $15 \mathrm{~kg}$ load, or even reached to $82 \%$ with the $25 \mathrm{~kg}$ load. Also, the larger the lifting load was, the higher the prevalence of spasm was. Spasm is usually associated with some type of micro-damage developing in the passive viscoelastic tissues of the lumbar spine $[31,33]$. The damage of ligamentous tissue could trigger spasms in the associated muscles [22], which is manifested by LBD, a clinical symptom in patients $[1,11,30]$.

There were some limitations that may affect the generalization of the results of this study. First, there were no female participants who are thought to show a different response under the same load lifting conditions $[23,31]$. Second, the load was the same for every participant. The response to a large load would probably be different if the load, relative to body mass, was lifted during the performance of a trunk flexion-extension exercise as Plamondon et al. [23] suggested. Third, the weight variation of the large load lifting in this study was only from 15 to $25 \mathrm{~kg}$. For safety reasons, a load >25 kg was not selected. However, according to the tendency of spasm and muscle activation in NEMG signical in the study, it could be considered that the higher prevalence of spasms and higher muscle activation intensity could occur when the lifting load was $>25 \mathrm{~kg}$. Fourth, this study involved only EMG. In future studies, investigating the kinetic and kinematical variables, together with EMG, may be helpful for us to understand the mechanism of load transfer in the lumbar spine under a large load condition similar to the investigation by Howarth and Mastragostino [13]. 


\section{Conclusions}

The general conclusion drawn from the results of this study is that during the performance of a trunk flexionextension exercise with a large lifting load, the muscle activation intensity of the bilateral ES significantly increased to compensate for passive tissues during the relaxation period. In addition, spasms on bilateral ES muscle were observed in more than $45 \%$ participants. The significant increase tendency in muscle activation together with a high prevalence of spasms indicates that a low back disorder may develop during the performance of a flexionextension exercise with a large lifting load.

\section{Abbreviations}

CDC: Center for disease control and prevention; EMG: Electromyography; ES: Erector spinae; FRP: Flexion relaxation phenomenon; LBD: Low back disorder; LBP: Low back pain; MAV: Mean absolute value; MVC: Maximal voluntary contractions; NEMG: Mean normalized EMG

\section{Acknowledgements}

Not applicable.

\section{Funding}

No funding was obtained for this study.

\section{Availability of data and materials}

The raw data underlying the conclusions made in this study are located at Biomechanics Lab, College of Physical Education, Shandong Normal University. The corresponding author can be contacted to request the raw data.

\section{Authors' contributions}

YM, as the first author, made contributions to design, acquisition and analysis of data. She was involved in drafting the manuscript. XS, as a corresponding author, made substantial contributions to conception and design, and interpretation of data. He was also involved in drafting the manuscript, revising it critically for important intellectual content. All authors have read and approved the manuscript, and ensure that this is the case.

\section{Ethics approval and consent to participate}

The study was approval by the local ethics committee in College of Physical Education, Shandong Normal University. Participants read and signed a consent form before participating in the study.

\section{Consent for publication}

Written consent was obtained to publish the image in Fig. 1.

\section{Competing interests}

The authors declare that they have no competing interests.

\section{Publisher's Note}

Springer Nature remains neutral with regard to jurisdictional claims in published maps and institutional affiliations.

Received: 13 February 2017 Accepted: 20 November 2017 Published online: 29 November 2017

\section{References}

1. Ahern DK, Follick MJ, Council JR, Laser-Wolston N, Litchman H. Comparison of lumbar paravertebral EMG patterns in chronic low back pain patients and non-patient controls. Pain. 1988:34:153-60.

2. Andersson GB. Epidemiological features of chronic low-back pain. Lancet. 1999:354:581-5.

3. Borenstein DB. Epidemiology, etiology, diagnostic evaluation, and treatment of low back pain. Current Opinion in Rheumatology. 2001;13:128-34.

4. Brandt M, Madeleine P, Ajslev JZ, Jakobsen MD, Samani A. Participatory intervention with objectively measured physical risk factors for musculoskeletal disorders in the construction industry: study protocol for a cluster randomized controlled trial. BMC Musculoskeletal Disorders. 2015; 16(1):302.

5. Centers for Disease Control and Prevention. Prevalence and most common causes of disability among adults_-United States. MMWR. 2009:58:421-6.

6. Dankaerts W, O'Sullivan PB, Burnett AF, Straker LM, Danneels LA. Reliability of EMG measurements for trunk muscles during maximal and sub-maximal voluntary isometric contractions in healthy controls and CLBP patients. Journal of Electromyography and Kinesiology. 2004;14(3):333-42.

7. Dreischarf M, Shirazi-Adl A, Arjmand N, Rohlmann A, Schmidt H. Estimation of loads on human lumbar spine: A review of in vivo and computational model studies. Journal of Biomechanics. 2016:49(6):833-45.

8. Floyd WF, Silver PHS. Function of erectors spinae in flexion of the trunk. Lancet. 1951:1:133-4.

9. Floyd WF, Silver PHS. The function of erectors spinae muscles in certain movements and postures in man. Journal of Physiology. 1995;129(1):184-203.

10. Golding JSR. Electromyography of the erector spinae in low back pain. Postgraduate Medical Journal. 1952;28:401-6.

11. Haig A, Wiesman G, Haugh L, Pope M, Grobler L. Prospective evidence for change in paraspinal muscle activityafter herniated nucleus pulposus. Spine. 1993;18:926-30

12. Holleran K, Pope M, Haugh L, Absher R. The response of the flexionrelaxation phenomenon in the low back to loading. The lowa Orthopaedic Journal. 1995:15:24-8.

13. Howarth SJ, Mastragostino P. Use of kinetic and kinematic data to evaluate load transfer as a mechanism for flexion relaxation in the lumbar spine. Journal of Biomechanical Engineering. 2013;135(10):101004-6.

14. Hu B, Shan X, Zhou J, Ning X. The effects of stance width and foot posture on lumbar muscle flexion-relaxation phenomenon. Clinical Biomechanics. 2014;29:311-6.

15. Kippers $\mathrm{V}$, Parker AW. Posture related myoelectric silence of erector spinae during trunk flexion. Spine. 1984;9:740-5.

16. Kostova V, Koleva M. Back disorders (low back pain, cervicobrachial and radicular syndromes) and some related risk factors. Journal of Neurological Science. 2001;192:17-25.

17. Leinonen V, Kankaanpaa M, Airaksinen O, Back HO. Hip extensor activities during flexion/extension: effects of low back pain and rehabilitation. Archives of Physical Medicine and Rehabilitation. 2000;81:32-7.

18. Luo X, Pietrobon R, Sun SX, Liu GG. Estimates and patterns of direct health care expenditures among individualswith back pain in the United States. Spine. 2003;29:79-86.

19. Marras WS, Lavender SA, Leurgans SE, Fathallah FA, Fergusons SA, Allread WG. Biomechanical risk factors for occupationally related low-back disorders. Ergonomics. 1995;38:377-410.

20. Nelson-Wong E, Callaghan JP. Is muscle co-activation a predisposing factor for low back pain development during standing? A multifactorial approach for early identification of at-risk individuals. Journal of Electromyography and Kinesiology. 2010;20:256-63.

21. Panjani MM. Clinical spinal instability and low back pain. Journal of Electromyography and Kinesiology. 2003;13:371-9.

22. Pedersen H, Blunk C, Gardner G. The anatomy of lumbosacral posterior ram and meningeal branches of spinal nerves. Journal of Bone and Joint Surgery. 1956;38:377-91.

23. Plamondon A, Lariviere C, Denis D, Mecheri H, Nastasia I. Difference between male and female workers lifting the same relative load when palletizing boxes. Applied Ergonomics. 2017;60(93-102):2017.

24. Rodacki ALF, Luiz NE, Provensi CLG, Rodacki CLN, Dezan VH. Body mass as a factor in stature change. Clinical Biomechanics. 2005;20:799-805.

25. Sarti MA, Liso'n JF, Monfort M, Fuster MA. Response of the FlexionRelaxation Phenomenon Relative to the Lumbar Motion to Load and Speed. Spine. 2001;26(18):E421-6.

26. Schultz AB, Haderspeck-Grib K, Sinkora G, Warwick DN. Quantitative studies of the flexion-relaxation phenomenon in the back muscles. Journal of Orthopeadic Research. 1985;3:189-97.

27. Shan X, Wei $Y$, Chen Z, Fan L, Shi W, Yang S. Effect of leg support on muscle cross-correlation of bilateral erector spinae during trunk flexionextension performance. Gait \& Posture. 2014;39:161-5.

28. Shan $X$, Zhang $Y$, Zhang $T$, Chen Z, Wei Y. Flexion relaxation of erector spinae response to spinal shrinkage. Journal of Electromyography and Kinesiology. 2012;22:370-5

29. Shin G, D'Souza C, Liu Y-H. Creep and Fatigue Development in the Low Back in Static Flexion. Spine. 2009;34(17):1873-8. 
30. Shivonen T, Partanen J, Hanninen O, Soimakallio S. Electric behavior of low back muscles during lumbar pelvic rhythm in low back pain and ealthycontrols. Archive of Physical Medicine and Rehabilitation. 1991;71: 1080-7.

31. Solomonow M, Baratta RV, Banks V, Freudenberger C, Zhou B. Flexionrelaxation response to static lumbar flexion in males and females. Clinical Biomechanics. 2003;18(4):273-9.

32. Toussain HM, de Winter AF, de Looze Y, Van Dieen YJ, Kingma I. Flexion relaxation during : implications for torque production by muscle activity and tissue strain at the lumbo-sacral joint. Journal of Biomechanics. 1995; 28(2):199-210.

33. Williams M, Solomonow M, Zhou B, Baratta R, Harris M. Multifidus Spasms Elicited by Prolonged Lumbar Flexion. Spine. 2005;25(22):2916-24.

34. Winter DA. "Biomechanics and Motor Control of Human Movement." third edit. Hoboken: John Wiley \& Sons Inc.2005.

35. Xu Y, Bach E, Orhede E. Work environment and low-back pain: the influence of occupational activities. Journal of Occupational and Environmental Medicine. 1997;54:741-5.

Submit your next manuscript to BioMed Central and we will help you at every step:

- We accept pre-submission inquiries

- Our selector tool helps you to find the most relevant journal

- We provide round the clock customer support

- Convenient online submission

- Thorough peer review

- Inclusion in PubMed and all major indexing services

- Maximum visibility for your research

Submit your manuscript at www.biomedcentral.com/submit
Biomed Central 